\title{
Liver Parenchyma Perforation following Endoscopic Retrograde Cholangiopancreatography
}

\author{
Hiroto Kayashima Toru Ikegami Yuta Kasagi \\ Gen Hidaka Koji Yamazaki Noriaki Sadanaga \\ Hiroyuki Itoh Yasunori Emi Hiroshi Matsuura \\ Kenichiro Okadome
}

Department of Surgery, Saiseikai Fukuoka General Hospital, Fukuoka, Japan

\section{Key Words}

Endoscopic retrograde cholangiopancreatography · Sphincterotomy · Complication . Guide wire · Liver injury

\begin{abstract}
Although endoscopic retrograde cholangiopancreatography (ERCP) is an effective modality for the diagnosis and treatment of biliary and pancreatic diseases, it is still related with several severe complications. We report on the case of a female patient who developed liver parenchyma perforation following ERCP. She underwent ERCP with sphincterotomy and extraction of a common bile duct stone. Shortly after ERCP, abdominal distension was identified. Abdominal computed tomography revealed intraabdominal air leakage and leakage of contrast dye penetrating the liver parenchyma into the space around the spleen. Since periampullary perforation related to sphincterotomy could not be denied, she was referred for immediate surgery. Obvious perforation could not be found at surgery. Cholecystectomy, insertion of a T tube into the common bile duct, placement of a duodenostomy tube and drainage of the retroperitoneum were performed. She did well postoperatively and was discharged home on postoperative day 28. In conclusion, as it is well recognized that perforation is one of the most serious complication related to ERCP, liver parenchyma perforation should be suspected as a cause.
\end{abstract}

\section{Introduction}

The first endoscopic pancreatogram was obtained in 1968 [1], and in 1974, biliary sphincterotomy was first described [2]. This was followed by the first report of 
papillotomy for the management of choledocholithiasis [3], and in subsequent years numerous endoscopic techniques evolved to address pancreaticobiliary disease. As computerized axial tomography and magnetic resonance imaging have improved, endoscopic retrograde cholangiopancreatography (ERCP) has evolved from primarily a diagnostic procedure into primarily a therapeutic procedure. As the indications for ERCP have increased, a greater focus on recognizing and preventing complications has emerged. Indeed, ERCP is a well-established effective procedure for the diagnosis and treatment of biliary and pancreatic diseases, however, various complications including pancreatitis, duodenal or common bile duct (CBD) perforation, hemorrhage, infection, and general cardiac and pulmonary complications still may occur [4]. It was reported that, in the 16,855 patients evaluated, ERCP-specific morbidity totaled 1,154 (6.85\%) [5]. ERCP-related perforation is one of the most serious complications and its incidence was reported from 0.12 to $0.60 \%$ [4-6]. It is generally agreed that some ERCP-related perforations can be successfully managed without surgery, however, it is difficult to define these patients. ERCP-related perforation is classified into guide wire perforation of the bile duct or pancreatic duct, periampullary perforation related to sphincterotomy, and duodenal perforation remote from the papilla [7]. Guide wire perforation is usually recognized in the bile duct or pancreatic duct, and penetration of the liver parenchyma is rare. We herein report on the case of a female patient who developed liver parenchyma perforation due to guide wire following ERCP.

\section{Case Report}

We report on the case of a 77-year-old Japanese woman who presented with right upper quadrant abdominal pain, nausea, and slight jaundice. Her serum levels of total bilirubin and alkaline phosphatase were high, up to $3.7 \mathrm{mg} / \mathrm{dl}$ (normal range $0.3-1.2 \mathrm{mg} / \mathrm{dl}$ ) and $513 \mathrm{IU} / \mathrm{l}$ (normal range 115-359 IU/l), respectively. Abdominal computed tomography (CT) revealed dilatation of the CBD. She underwent ERCP with sphincterotomy and extraction of the CBD stone for the diagnosis of choledocholithiasis. Shortly after ERCP, abdominal distension, hypotension, tachycardia, and tachypnea were identified. She underwent emergency abdominal CT, which revealed intraabdominal air leakage and leakage of contrast medium penetrating the liver parenchyma into the space around the spleen (fig. 1). Furthermore, ERCP imaging showed deep cannulation of the guide wire into the left intrahepatic bile duct, retrospectively (fig. 2). Liver parenchyma perforation due to the guide wire was most likely, however, periampullary perforation related to sphincterotomy could not be denied. Therefore, she was referred for immediate surgery.

The emergency operation was performed about $5 \mathrm{~h}$ after ERCP. At laparotomy, there was no bile leakage, and neither obvious liver parenchyma perforation nor periampullary perforation was found. However, periampullary perforation is often difficult to identify in the operating room. Therefore, cholecystectomy, insertion of a $\mathrm{T}$ tube into the $\mathrm{CBD}$, and placement of a duodenostomy tube were performed to divert bile and succus entericus away from the duodenal ampulla. Finally, drainage of the retroperitoneum was performed.

Her postoperative course was uneventful. On postoperative day (POD) 6, she resumed meals. The duodenostomy tube and the T tube were removed on POD 18 and POD 25, respectively. She was discharged home on POD 28. She is doing well 4 months after surgery under no therapy.

\section{Discussion}

The management of ERCP-related perforation is controversial. Some authors have advocated immediate surgery for all endoscopic shincterotomy perforations [8], but others have reported that most perforations may be managed without surgery [9]. Wu et 
al. [6] summarized as follows: guide wire perforation is benign in nature and can be treated with medical therapy. Periampullary perforation is associated with a high morbidity and mortality and should have aggressive surgery. Delay in diagnosis and surgery results in a worse outcome. As a result, there should be a high index of suspicious for perforation in any patient with significant abdominal pain following therapeutic ERCP, and an early CT scan should be considered in these patients. Duodenal perforation is least common and requires surgery.

Guide wire perforation is usually recognized in the bile duct or pancreatic duct by extravasation of contrast dye on fluoroscopy during ERCP, and penetration of the liver parenchyma is rare. The present case is a rare case of a patient who developed liver parenchyma perforation due to guide wire following ERCP. Although immediate surgery was performed about $5 \mathrm{~h}$ after ERCP, obvious liver parenchyma perforation could unfortunately not be found. It is possible that the perforation site had been very tiny and had healed naturally at surgery. In the present case, we performed cholecystectomy, insertion of a $\mathrm{T}$ tube into the CBD, and placement of a duodenostomy tube. The reason was that periampullary perforation related to sphincterotomy still could not be denied during the operation. Periampullary perforation is often difficult to identify in the operating room, and a delay in treatment will lead to death. Therefore, an aggressive surgery to divert bile and succus entericus away from the perforation site should be performed.

In conclusion, as it is well recognized that perforation is one of the most serious complications related to ERCP, liver parenchyma perforation due to guide wire should be suspected as a cause.

\section{Disclosure Statement}

None of the authors has any conflict of interest. 


\begin{tabular}{|c|c|c|c|}
\hline $\begin{array}{l}\text { Case Reports in } \\
\text { Gastroenterology }\end{array}$ & \begin{tabular}{|l} 
Case Rep Gastroenterol 2011:5:487-491 \\
Dol: 10.1159/0003311135
\end{tabular} & $\begin{array}{l}\text { Published online: } \\
\text { August 24, } 2011\end{array}$ & $\begin{array}{l}\text { O } 2011 \text { S. Karger AG, Basel } \\
\text { ISSN 1662-0631 } \\
\text { www.karger.com/crg }\end{array}$ \\
\hline
\end{tabular}
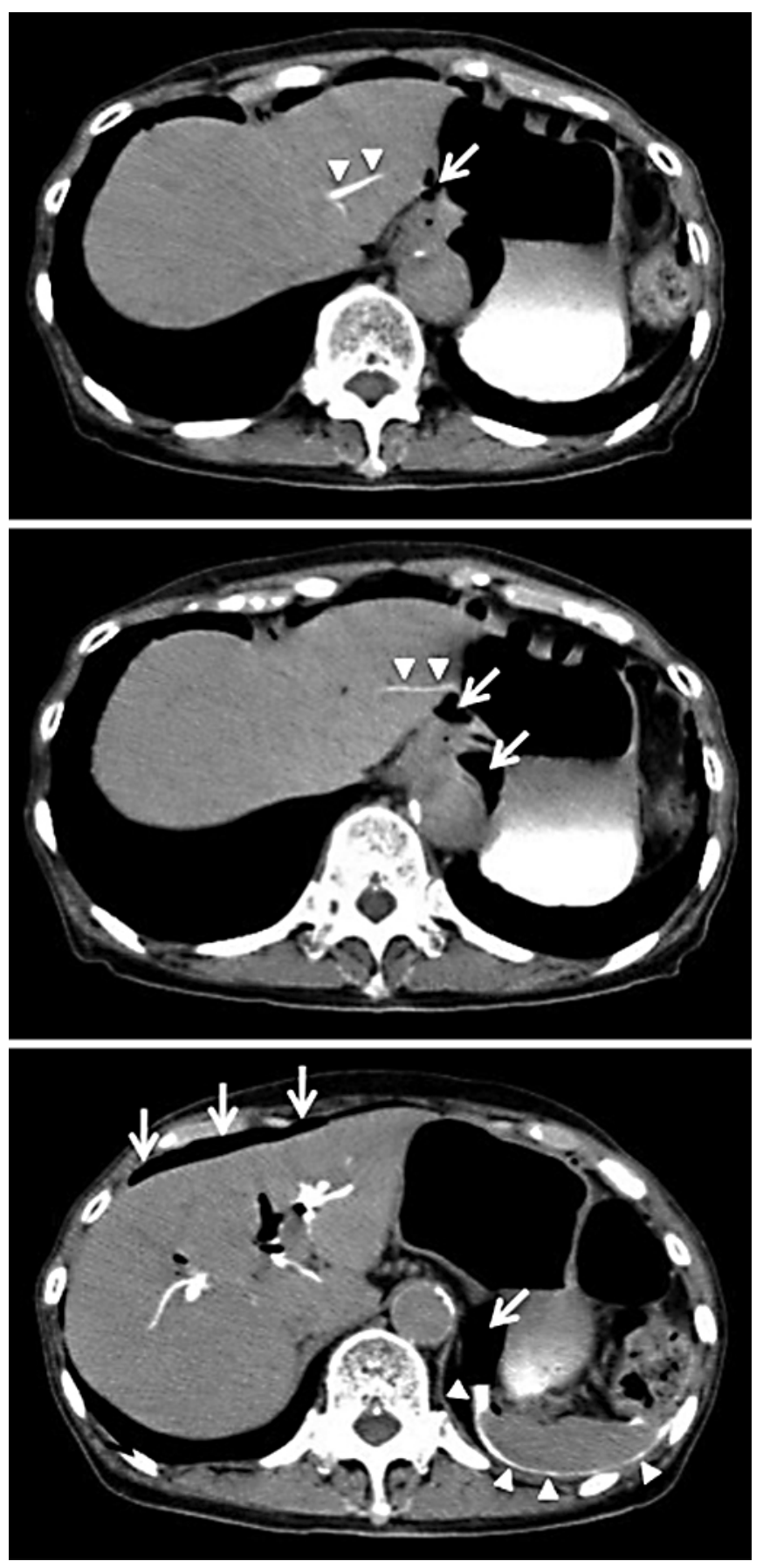

Fig. 1. Emergency abdominal CT revealed intraabdominal air leakage (arrows) and leakage of contrast medium penetrating the liver parenchyma into the space around the spleen (arrowheads). 


\begin{tabular}{|c|c|c|c|}
\hline $\begin{array}{r}\text { Case Reports in } \\
\text { Gastroenterolooy }\end{array}$ & $\begin{array}{l}\text { Case Rep Gastroenterol 2011;5:487-491 } \\
\text { DOI: 10.1159/000331135 }\end{array}$ & $\begin{array}{l}\text { Published online: } \\
\text { August 24, } 2011\end{array}$ & $\begin{array}{l}\text { () } 2011 \text { S. Karger AG, Basel } \\
\text { ISSN } 1662-0631 \\
\text { www.karger.com/crg }\end{array}$ \\
\hline
\end{tabular}

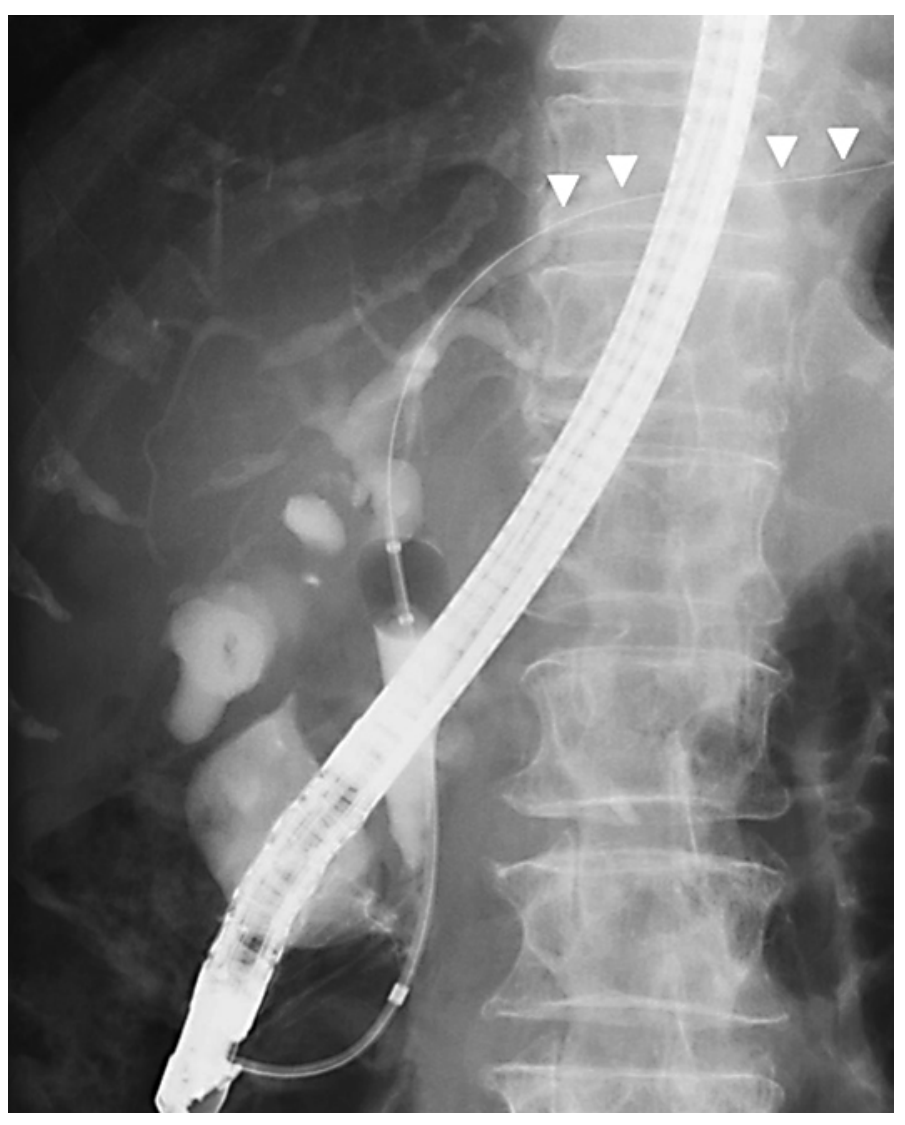

Fig. 2. ERCP imaging showed deep cannulation of the guide wire into the left intrahepatic bile duct (arrowheads).

\section{References}

1 McCune WS, Shorb PE, Moscovitz H: Endoscopic cannulation of the ampulla of vater: a preliminary report. Ann Surg 1968;167:752-756.

2 Peel AL, Hermon-Taylor J, Ritchie HD: Technique of transduodenal exploration of the common bile duct. Duodenoscopic appearances after biliary sphincterotomy. Ann R Coll Surg Engl 1974;55:236-244.

3 Zimmon DS, Falkenstein DB, Kessler RE: Endoscopic papillotomy for choledocholithiasis. N Engl J Med 1975;293:1181-1182.

4 Colton JB, Curran CC: Quality indicators, including complications, of ERCP in a community setting: a prospective study. Gastrointest Endosc 2009;70:457-467.

5 Andriulli A, Loperfido S, Napolitano G, Niro G, Valvano MR, Spirito F, Pilotto A, Forlano R: Incidence rates of post-ERCP complications: a systematic survey of prospective studies. Am J Gastroenterol 2007;102:1781-1788.

6 Wu HM, Dixon E, May GR, Sutherland FR: Management of perforation after endoscopic retrograde cholangiopancreatography (ERCP): a population-based review. HPB (Oxford) 2006;8:393-399.

7 Stapfer M, Selby RR, Stain SC, Katkhouda N, Parekh D, Jabbour N, Garry D: Management of duodenal perforation after endoscopic retrograde cholangiopancreatography and sphincterotomy. Ann Surg 2000;232:191-198.

8 Booth FV, Doerr RJ, Khalafi RS, Luchette FA, Flint LM Jr: Surgical management of complications of endoscopic sphincterotomy with precut papillotomy. Am J Surg 1990;159:132-135.

-9 Chung RS, Sivak MV, Ferguson DR: Surgical decisions in the management of duodenal perforation complicating endoscopic sphincterotomy. Am J Surg 1993;165:700-703. 